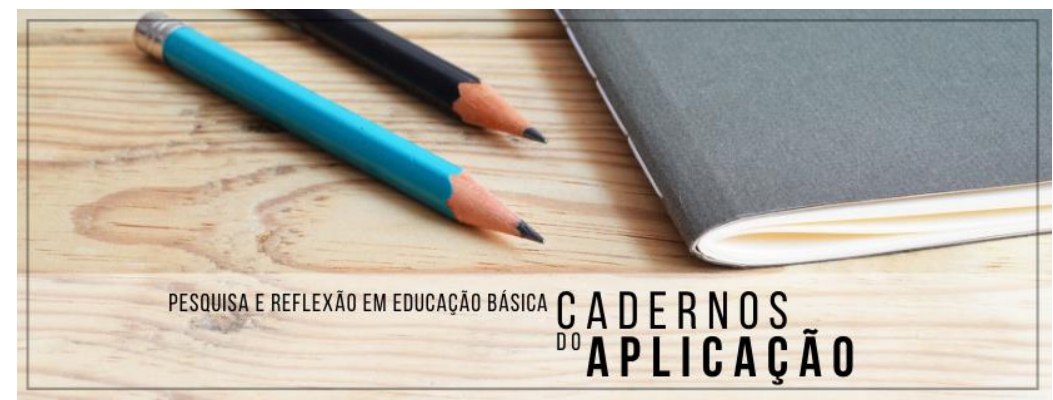

Cadernos do Aplicação

https://seer.ufrgs.br/CadernosdoAplicacao

Publicação Ahead of Print

ISSN 2595-4377 (online)

Porto Alegre | jul-dez. 2021 | v.34 | n.2

\title{
Vozes dissonantes: o negro na literatura potiguar
}

\author{
Francisco Humberlan Arruda de Oliveira ${ }^{1}$ \\ Carlos Antonio de Paiva Holanda ${ }^{2}$
}

\begin{abstract}
Resumo: A presença do negro na literatura potiguar é um estudo incipiente, seja pela quase ausência de pesquisas sobre o tema ou, ainda, pela caracterização da literatura regional que sobrepõe aspectos temáticos e estilísticos da produção poética do Rio Grande do Norte. Nesse sentido, este artigo objetiva analisar a imagem construída do negro no âmbito da escrita literária regional, os fatores condicionantes que permeiam a presença ou ausência da negritude como autoria/temática, assim como a categoria do regional como um espaço suprarregional que ultrapassa o conceito de regionalismo como lugar geográfico para entendê-lo na perspectiva de ambiente histórico-cultural representativo. Para isso, o trabalho metodológico, de análise documental e abordagem qualitativa, precisa se deter na crítica dos fundamentos teóricos, literários e culturais que permeiam a figura do negro na poesia potiguar na primeira metade do século XX. Tomamos como aporte teórico a noção de suprarregional de Arendt (2011), o conceito de literatura afrodescendente de Duarte (2002) e de imagologia de Ribeiro (2005). A nossa hipótese é a de que a escrita poética potiguar é sucumbida por estéticas decadentes e regionalismo, corroborando para que a imagem do negro seja minimizada e a sua representação ocorra por meio de vozes dissonantes.
\end{abstract}

Palavras-chave: Literatura potiguar. Negro. Poesia regional. Suprarregional.

\section{Dissonant voices: the black man in the potiguar literature}

\begin{abstract}
The presence of the black man in the Potiguar Literature is an incipient field of study, either because of the absence of research on the subject or, still, because the characterization of regional literature overlaps other thematic and stylistic aspects of the poetic production of Rio Grande do Norte. In this sense, this article aims to analyze the constructed image of the black man in regional literary writing, the historical conditioning factors that permeate the presence or absence of blackness as an author/theme, as well as the category of the regional as a supra-regional space that goes beyond the concept of regionalism as a geographical place to understand it from the perspective of a representative of an historical-cultural environment. The methodological work needs to focus on the critique of the theoretical, literary, and cultural foundations that permeate the figure of the black man in Potiguar poetry in the first half of the twentieth century. The theoretical support is the notion of supraregional by Arendt (2011), the concept of Afro-descendant literature by Duarte (2002) and the concept of imagology
\end{abstract}

\footnotetext{
${ }^{1}$ Mestre em Letras; Instituto Federal de Educação, Ciência e Tecnologia do Rio Grande do Norte (IFRN); E-mail: francisco.arruda@ifrn.edu.br; ORCID iD: https://orcid.org/0000-0003-3351-8562

2 Aluno do Ensino Médio Técnico Integrado em Alimentos no IFRN, Campus Pau dos Ferros; E-mail: carlos.p@escolar.ifrn.edu.br
} 
by Ribeiro (2005). Our hypothesis is that Potiguar poetic writing is succumbed to already decadent aesthetics and category of the regional.

Keywords: Potiguar literature. Black. regional poetry. Suprarregional.

\title{
Voces disonantes: el negro en la literatura potiguar
}

\begin{abstract}
Resumen: La presencia de negros en la literatura Potiguar es un estudio incipiente, ya sea por la casi ausencia de investigaciones sobre el tema o, también, por la caracterización de la literatura regional que traslapa aspectos temáticos y estilísticos de la producción poética de Rio Grande do Norte. En este sentido, este artículo tiene como objetivo analizar la imagen construida de los negros en el ámbito de la escritura literaria regional, los condicionantes que permean la presencia o ausencia de la negritud como autoría / temática, así como la categoría de lo regional como espacio suprarregional que va más allá del concepto de regionalismo como lugar geográfico para entenderlo desde la perspectiva de un entorno histórico-cultural representativo. Para ello, el trabajo metodológico, análisis de documentos y enfoque cualitativo, debe centrarse en la crítica de los fundamentos teóricos, literarios y culturales que impregnan la figura del negro en la poesía Potiguar en la primera mitad del siglo XX. Tomamos la noción de suprarregional de Arendt (2011) como soporte teórico, el concepto de literatura afrodescendiente de Duarte (2002) y el imaginario de Ribeiro (2005). Nuestra hipótesis es que la escritura poética Potiguar es sucumbida por la estética decadente y el regionalismo.
\end{abstract}

Palabras clave: Literatura potiguar. Negro. Poesía regional. Suprarregional.

\section{Introdução}

A cultura passa a ser viabilizada cada vez mais nos estudos do texto literário em que diversos temas sociais/culturais se tornam pontos de partida para representação e compreensão do texto literário. Entretanto, mesmo abordando as imagens do negro na poesia, esta pesquisa não tomará os Cultural Studies como método ou crítica literária a ser seguida.

A explicação reside no fato de que os estudos culturais analisam o objeto literário a partir de posições políticas, ideológicas e sociais que sucumbem os elementos estéticos do texto, isto é, parte do que é externo à obra para aquilo que lhe é interno (OLIVEIRA; CAMARGO, 2019). Em outras palavras, a cultura - como elemento externo ao texto literário - ganha mais importância que a linguagem literária na perspectiva dos Estudos Culturais.

A proposição desta pesquisa não é relativizar os condicionantes que estão na produção do texto literário, mas utilizá-los na perspectiva indicada por Antonio Candido (2006), o qual 
defende que a realidade externa ao texto seja coadjuvante em relação aos elementos estéticos do objeto literário, isto é, “o que é externo à obra não é, necessariamente, descartado, mas não pode ser tomado como princípio para sua análise.” (OLIVEIRA; CAMARGO, 2019, p. 18).

O “externo” à obra - que são os condicionantes históricos, sociais, culturais e literários - devem se juntar ao texto, à linguagem literária formando um objeto complexo, mas, ao mesmo tempo, único. O grande problema dos Estudos Culturais de focar na cultura como uma chave de leitura literária é criar representações que atendem muito mais à expectativa do tempo do pesquisado que, necessariamente, ao da produção e circulação do texto literário analisado.

O elo entre realidade e literatura constitui um ponto elementar no processo complexo de produção, leitura e análise de obras. São duas instâncias da escrita poética que não podem ser negligenciadas nos estudos literários, daí que perspectivas críticas e teóricas diversas - desde o formalismo russo passando pela estilística e estudos culturais - discutem a literatura como representação ou, ainda, representativa.

Tomando o papel da literatura proposto por Aristóteles (1984) como o de "reapresentar" o real, isto é, de recriar a realidade na ficção, é possível, a partir dessa perspectiva, discutir aspectos como a questão identitária de grupos sociais e a noção de literatura regional, pois não se constituem categorias fixas.

Isso fica claro observando a forma como o texto literário se desenvolve a partir da relação que se estabelece no discurso entre autor/leitor, isto é, produção e recepção, a presença ou ausência de temáticas é produto de fatores condicionantes como o histórico, social, cultural e regional. Nesse sentido, o próprio conceito de literatura regional o limita a uma determinada região, só alcançando o universalismo por meio de critérios estéticos como o belo e o sublime, isto é, as impressões de leitura que o leitor possa ter sobre a obra são desconsideradas (ARENDT, 2011).

Para além de uma reflexão sobre a noção do que se considera regional ou não, este artigo também pretende analisar as imagens suscitadas pela poesia potiguar. Essa escolha se justifica por três motivos: i) os estudos literários, na contemporaneidade, têm privilegiado o texto em prosa, o que é atestado pelo número significativo de pesquisas em nível de pós-graduação ${ }^{3}$; ii)

\footnotetext{
3 A afirmação se aporta na pesquisa que foi realizada nos bancos de teses e dissertações do programa de PósGraduação em Estudos da Linguagem da Universidade Federal do Rio Grande do Norte (UFRN) em que as
} 
no ensino da literatura - tanto no ensino superior, como no básico - as leituras recaem sobre a narrativa: contos, crônicas, romances, novelas, etc ${ }^{4}$. e; iii) como este trabalho é fruto de projeto de pesquisa desenvolvido em conjunto com alunos do ensino médio técnico de uma instituição federal de ensino situado no interior do Estado do Rio Grande do Norte - IFRN Campus Pau dos Ferros - trabalhar com poemas de homens e mulheres negras é uma forma de fomentar o espaço, reduzido, destinado ao poema tanto nas análises, como na leitura.

Serão analisados aqui alguns poemas representativos da primeira metade do século XX em que o negro aparece como temática ou autoria: Penas de Garça, de Auta de Souza; Aboio, de Henrique Castriciano e $A$ voz da justiça, de Segundo Wanderley. Evidente que apenas a análise de três poemas não é o suficiente para caracterizar a produção literária sobre o negro no Rio Grande do Norte, contudo, quando considerado a escassez de autores negros, o hiato no que tange às figurações do negro entre os anos iniciais do século $\mathrm{XX}$ e a poesia marginal potiguar, e o espaço para analisar demais poemas e poetas, podemos inferir que o corpus analisado é representativo do quadro da literatura regional e da dissonância do negro na produção poética norte-riograndense.

Como passos metodológicos foram discutidos os textos teóricos com os alunos que participaram do projeto de pesquisa para, em seguida, proceder à coleta de dados, por décadas, de 1900 a 1950. Por conta da pandemia, a pesquisa foi realizada de forma remota por meio de busca em jornais da época no site da Hemeroteca da Biblioteca Nacional. Nas análises, considerou a crítica dos fundamentos teóricos, literários e culturais que permeiam a figura do negro na poesia potiguar na primeira metade do século $\mathrm{XX}$, como o contexto de produção e circulação dos poemas e o conhecimento teórico sobre a temática de forma que favorecessem a compreensão das imagens do negro na poesia potiguar.

Como aporte teórico para analisar as imagens suscitadas nos poemas da literatura potiguar, este artigo se utilizará da imagologia, a partir de Celeste Sousa (2007) e Daniel Henri-

\footnotetext{
pesquisas sobre os textos em prosa são a maioria. A poesia surge apenas em $3 \%$ dos trabalhos disponibilizados no repositório on-line.

${ }^{4}$ Por mais que haja a previsão do estudo do poema nas ementas das disciplinas de Língua Portuguesa e Literatura Brasileira do Instituto Federal de Educação, Ciência e Tecnologia do rio Grande do Norte (IFRN), a prática docente nos atesta uma predileção pelos textos em prosa. É um dado pautado, ainda, no embasamento empírico, que carece de estudo específico, mas encontra respaldo em outros ambientes institucionais no Rio Grande do Norte, além do IFRN.
} 
Cadernos do Aplicação

https://seer.ufrgs.br/CadernosdoAplicacao

Publicação Ahead of Print

ISSN 2595-4377 (online)

Pesquisa e ReFlexão em eduCação básica $C$ A D E R N O S

${ }^{0} A P L I C A C ̧ A ̃ O$

Porto Alegre | jul-dez. 2021 | v.34 | n.2

Pageaux (2011), da ideia de literatura afro-brasileira (DUARTE, 2002) e da forma analítica que reúne os elementos "internos" e "externos" de uma obra, proposta por Candido (2006). Somase a isso, o conceito de literatura regional de Joachimsthaler (2009) e Arendt (2011) que será usado para fundamentar as discussões acerca do regional e suprarregional na poesia potiguar. Passemos a detalhar sobre esses conceitos.

\section{A presença ou ausência traz uma imagem}

A imagologia, como investigação das imagens, faz parte da literatura comparada. Ela busca analisar que tipo e como as imagens de uma cultura passam a ser veiculadas em obras literárias internas ou estrangeiras. Nesse sentido, os estudos imagológicos buscam "a investigação não só da imagem, que os outros fazem de nós, mas também a imagem que fazemos de nós mesmos. E, além disso, trabalha igualmente, com a relação existente entre as imagens de outros países e estereótipos, clichês e preconceitos.” (RIBEIRO, 2005, p. 3).

A imagologia vai contribuir com este trabalho no intuito de compreender a imagem do negro dentro da literatura potiguar, pois ao levantar uma série de elementos condicionantes que corroboram para a construção da imagem da negritude, poderá ser observado se as imagens são carregadas de preconceitos e/ou clichês e se elas comprometem o espaço do negro na literatura regional.

Um dos elementos condicionantes que é possível alcançar por meio dos estudos imagológicos é o conceito de literatura regional, pois a regionalização da literatura favorece mais a criação da imagem do homem no sertão, no caso do nordeste, que a figura do negro. Isso tem origem nos estereótipos que a literatura nacional faz sobre os ambientes geográficos, o que é reproduzido de forma local.

Dessa forma, a ideia de literatura regional fica restrita ao ambiente geográfico, não contabilizando a perspectiva histórico-cultural, mas imagens que são consagradas e oriundas da divisão entre literatura universal e regional. Nesse sentido, o espaço para a negritude fica ainda mais reduzido, especialmente pelo preconceito, o que explica a ausência enquanto temática, na escrita regional. 


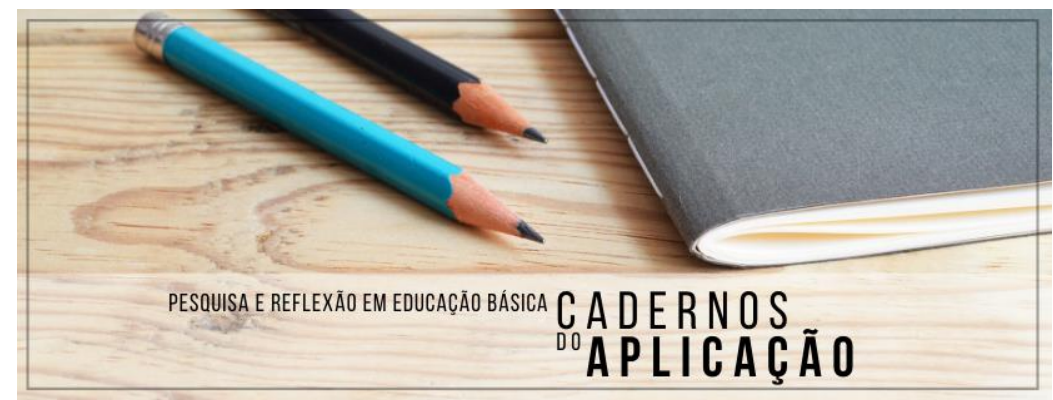

Cadernos do Aplicação https://seer.ufrgs.br/CadernosdoAplicacao

Publicação Ahead of Print

ISSN 2595-4377 (online)

Porto Alegre | jul-dez. 2021 | v.34 | n.2

Por outro lado, obras e autores, mesmo tendo a ambientação geográfica e a reprodução do estereótipo do sertão nordestino, não são considerados regionais, mas universais. Exemplo disso encontramos no chamado romance de 30, como Vidas Secas, de Graciliano Ramos, ou ainda, na contemporaneidade, como Milton Hatoum. Esses escritores não entram no conceito de literatura regional, mas por quê? A resposta passa pela crítica que é um juízo de valor em que o universal, como espaço cultural, tem mais peso que o regional:

Espaços culturais, por si sós, ainda não são regiões. Espaços culturais são somente áreas geográficas (e temporais) disseminadoras de diferentes bens culturais. Dito de outra forma: cada patrimônio cultural tem seu espaço cultural próprio (variável e capaz de expandir-se a qualquer momento por exportação): é assim com o gótico e o tango, a Bíblia e o McDonalds, o basco e os iglus, o garfo e a faca e as técnicas chinesas de respiração. As áreas disseminadoras de muitos desses bens culturais particulares recobrem em parte e acumulam-se em (e com) contextos particulares concretos, formando concentrações espaço-culturais ("culturas") que são forçosamente de caráter "sincrético", de proveniência intercultural... (JOACHIMSTHALER, 2009, p. 28).

Nesse sentido, a ideia de regional fica restrita a um espaço geográfico, daí que Arendt (2011) prefere o termo suprarregional, pois é uma literatura que não se distancia dos grandes centros culturais, ao contrário, por meio de elementos estéticos, circulação e temáticos ela alcança outros espaços culturais sem deixar de ser regional.

Como a literatura regional não se distancia do seu espaço cultural e a identidade local é reforçada por meio de imagens socioculturais herdadas, a temática na literatura regional é influenciada por esses condicionantes, assim como ela vai interferir na recepção das produções. Portanto, a partir da análise das imagens do negro na poesia é possível não só entender o lugar e a importância de temáticas como a escravidão, abolicionismo, preconceitos, entre outros, como também repensar o conceito de literatura regional não mais limitante ao ambiente.

Nesse sentido, buscar as imagens do negro na poesia regional do Rio Grande do Norte é interessante para entender a literatura representativa a partir da questão identitária em que ela se insere na construção poética, como defendia Antonio Candido (2006), e vislumbrar o regionalismo como suprarregional, isto é, os efeitos estéticos e temáticos sobre o leitor rompem com as fronteiras do espaço geográfico natural. Passemos a análise dos poemas. 


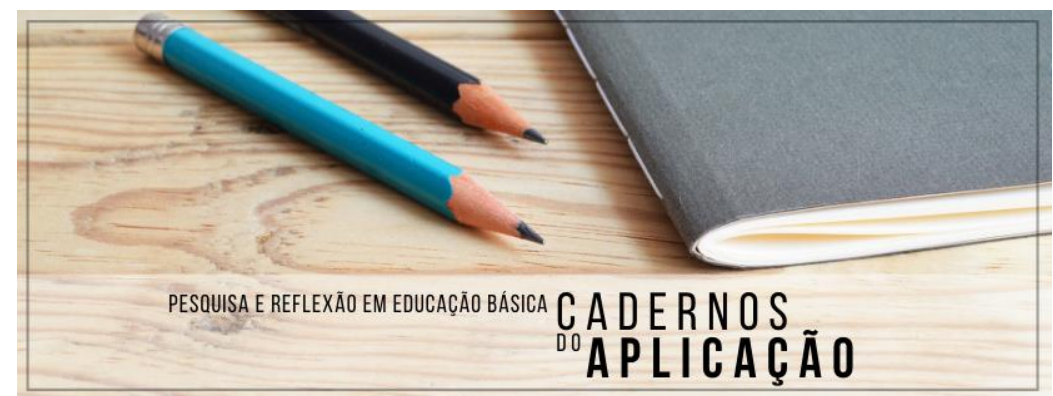

Cadernos do Aplicação https://seer.ufrgs.br/CadernosdoAplicacao Publicação Ahead of Print ISSN 2595-4377 (online) Porto Alegre | jul-dez. 2021 | v.34 | n.2

\section{Análise}

Partindo da constatação de que a questão identitária do negro ficou em segundo plano desde a época da escravidão e se alastrando no pós-abolição já que a cultura e a memória dos povos africanos e seus descendentes sofreram com a estigmatização e o preconceito, não é difícil imaginar a dificuldade da assunção das identidades culturais de homens e mulheres negras no Brasil do final do século XIX.

Segundo Duarte (2002), o conceito de literatura afrodescendente se encontra em construção, pois há diversos condicionantes que permitem a sua ampliação, entre eles a identidade. $\mathrm{O}$ ato de refutar as marcas identitárias - por questões que devem ser analisadas à luz de cada época - não apaga a inscrição de literários negros no âmbito da literatura afrobrasileira, ao contrário, são imagens que devem ser analisadas.

Nesse sentido, mesmo não abordando a questão do negro, é importante analisar produções poéticas como a escritora potiguar Auta de Souza. Escolhemos para este artigo o poema Penas de Garça, publicado na Revista do Rio Grande do Norte em 1899. O poema é constituído por 25 estrofes, cada uma com 4 versos, isto é, feito todo por quadras, estilo não muito comum para a época do simbolismo em que a preferência era o soneto.

Auta de Souza era uma mulher negra nascida no solo potiguar num tempo em que a produção poética regional ainda era incipiente. Contudo, mesmo não trazendo a temática do negro nos seus poemas, Auta de Souza se torna uma voz dissonante no cenário local, pois não só rompe a bolha geográfica, como acompanha o movimento literário nacional de forma concomitante.

Isso é um detalhe muito revelador já que a literatura potiguar sofrera de um "romantismo tardio", isto é, a literatura potiguar sempre esteve atrasada em relação às estéticas em evidência a nível nacional. Porém, Araújo (2004) vai se referir a nomes como Auta de Souza, Henrique Castriciano e Segundo Wanderley com o termo "pós-românticos", isto é, escritores que estavam em consonância com as estéticas literárias vigentes, tais como Romantismo, Simbolismo e Parnasianismo. Essa miscelânea literária aparece de forma contundente na escrita da poeta potiguar: 


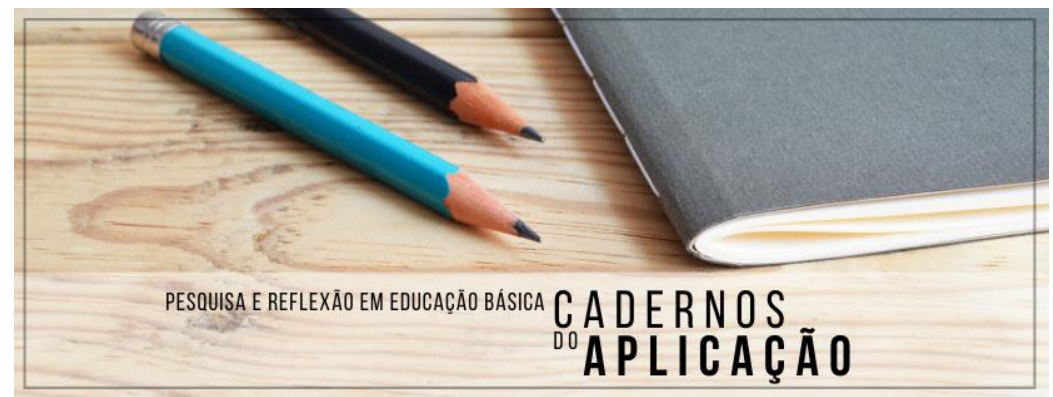

Cadernos do Aplicação

https://seer.ufrgs.br/CadernosdoAplicacao

Publicação Ahead of Print

ISSN 2595-4377 (online)

Porto Alegre | jul-dez. 2021 | v.34 | n.2

I

Responde-me, ó jurity,

Ao que te vou perguntar:

Por que é que o Dia sorri

E a Noite vive a chorar?

II

Não sabes? N'um sonho brando,

O Dia ri quando quer,

$E$ a Noite vive chorando,

Somente porque é mulher.

III

Quando eu nasci, no telhado,

Uma coruja cantou...

Dizia a chorar: coitado!

Um anjo do Céu voou.

A indagação ao juriti - que representa a fonte da memória, um oráculo - aparece fazendo a alternância entre o dia e a noite ou, ainda, com palavras que sugerem a dualidade como "luz e escuridão", "bem e mal", etc.. Essa carga pessimista sobre a vida e, em especial, sobre si, é própria do Simbolismo, em que as cores têm um papel decisivo na interpretação do mundo. No poema, as alusões às cores escuras reforçam alguns desconfortos: com a vida, com o amor e com a condição de ser mulher, no trecho acima.

Há também marcas de um Romantismo tardio por meio de uma idealização do eu feminino, das desilusões amorosas e de um exagero lírico:

\section{$\mathrm{V}$}

Meus sonhos andam no mundo

Em cantos negros dispersos...

São ondas de um mar profundo...

Ai! triste de quem faz versos!

VI

Nas noites de lua, eu canto

Para esquecer-me de ti.

Minh'alma soluçou tanto

Que o pranto já aborreci.

Vale salientar que esse poema se encontra publicado no único livro de poemas de Auta de Souza, Horto, o qual fora lançado pela A República e com prefácio de Olavo Bilac, portanto, não é possível dizer que se trata de uma obra regional, pois ela ultrapassa os limites geográficos, alcançando aqui, por meios de condicionantes críticos e editoriais, o que Arendt (2011) chama de suprarregional: 


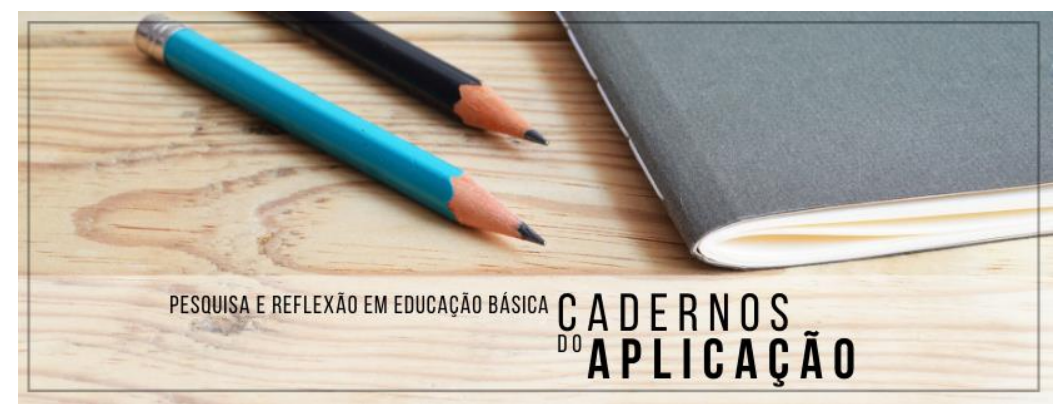

Cadernos do Aplicação

https://seer.ufrgs.br/CadernosdoAplicacao

Publicação Ahead of Print

ISSN 2595-4377 (online)

Porto Alegre | jul-dez. 2021 | v.34 | n.2

À valoração estética, Scheichl antepõe critérios sociológicos a fim de definir uma obra ou autor como regional ou suprarregional. Para isso, deve-se perguntar em quais meios o autor publicou, onde seus textos foram editados após a morte, a que público suas obras se dirigem e por quem elas de fato são ou foram lidas. Tal critério ajudaria a distinguir com mais propriedade a literatura regional e a literatura não regional, até porque haveria muita diferença entre um autor publicar na editora Krafft, em Hermannstadt, e na S. Fischer, em Berlim. Com isso, toca-se em questões referentes aos meios de produção e difusão das obras. (ARENDT, 2011, p. 221).

Ainda que a condição do negro não seja tematizada, é possível inferir que há uma imagem na ausência, pois evidencia o quanto a poesia de Auta de Souza está distante das discussões sobre a escravidão e a condição da população negra no pós-abolicionismo. A melancolia dos seus poemas advém do alinhamento com a estética simbolista e romancista nada tendo a ver com as questões sociais, culturais e raciais que envolviam a figura do negro em sua época, mesmo Auta de Souza sendo uma mulher negra:

É importante observar na sua poesia a obsessiva exaltação de elementos tidos como arianos puros. A poetisa, embora fosse de sangue negro, não defendia a sua cor, pelo contrário [sic] sempre cantava, como símbolos de pureza, crianças loiras de olhos azuis. (GONZAGA, 2014, p. 16).

Postura parecida também encontramos na poesia do seu irmão Henrique Castriciano. De perfil melancólico e triste, que refletiu na elaboração dos seus quatro livros de poesias, Ruínas, Iriações, Mãe e Vibrações, Castriciano, além de poeta, foi político, desempenhando os cargos de deputado estadual, vice-governador, procurador-geral do Estado e secretário geral, e foi o criador da Escola Doméstica de Natal - trazendo para o Rio Grande do Norte o modelo europeu de educação feminina em que a mulher era instruída no desempenho de funções domésticas no seio da família e de comportamento social.

A atuação política e literária de Henrique Castriciano, a importância do seu nome no cenário literário potiguar e a ausência de escritores negros na literatura norte-riograndense são condicionantes os quais precisam ser considerados no momento da análise do poema aqui selecionado no intuito de entender de qual literatura regional estamos a falar e qual é o lugar da negritude na poesia do Rio Grande do Norte.

Publicado em 1904 no jornal A República, o poema Aboio traz uma perspectiva da vida sertaneja no sertão do nordeste, marcada ora pela fartura decorrente do inverno, ora pela miséria 


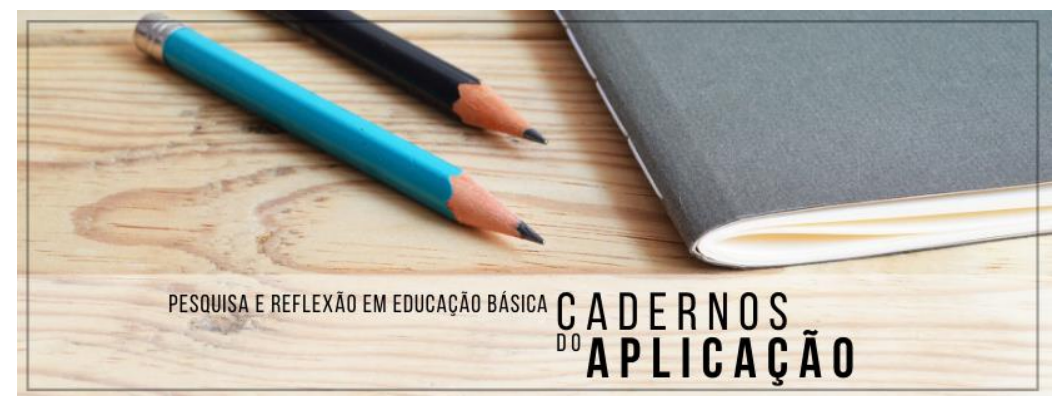

Cadernos do Aplicação

https://seer.ufrgs.br/CadernosdoAplicacao

Publicação Ahead of Print

ISSN 2595-4377 (online)

Porto Alegre | jul-dez. 2021 | v.34 | n.2

e fome proporcionadas pela seca. As condições ambientais ditam os rumos tomados pelo sertanejo durante sua jornada.

A leitura traz uma variedade de sentimentos contraditórios, tais como: tristeza, luto, saudades e alegrias. Embora o sertanejo tenha perdido familiares, ele cresceu e se desenvolveu como pessoa naquele lugar, por isso suas lembranças são acompanhadas por um tom leve e ameno. Nesse sentido, "a perspectiva saudosista que reveste o poema tende a aproximar seu autor da postura do folclorista e assim, também, dos propósitos de um regionalismo tradicional" (COSTA, 2013, p. 74-75).

Diferentemente de outros Estados, os negros escravizados no Rio Grande do Norte se transformaram em vaqueiros ou, ainda, empregados em atividades domésticas. Isso se explica pelo fato de o Estado não ter tido expressividade na cultura açucareira, mas sim na criação de gado (GONZAGA, 2014, p. 12). Contudo, é um equívoco a tese de que a população escravizada no Rio Grande do Norte fora amena ou inexistente ${ }^{5}$, mas que houve um processo de aglutinação entre o sertanejo e o negro.

No poema Aboio, a vida do sertanejo representa a de muitos outros e sua imagem pode estar veiculada a do negro, podemos inferir isso nos seguintes versos:

Essa trêmula queixa é o gemido e o brado

De uma raça infeliz, cujo longo passado

Simboliza o clamor da miséria e da fome

Procurando exprimir tanta angústia sem nome.

$$
\text { [...] }
$$

Ah, nós sentimos bem que fala a nossa terra!

É a raça cabocla, lusa e a africana

Procurando expressar tanta dor sobre-humana

Essa dorida voz, de ondulações estranhas

Triste através do espaço e através das montanhas,

É a mesma que veio entoando pelos mares

As orações de fé portuguesa;

Que, na língua tupi, em incertos cantares,

Primeiro celebrou nossa natureza;

Que, depois de sofrer as amarguras do eito,

Pobre raça infeliz, nos embalou no leito!

E como exprime bem o sussurro das matas!

O soluço dos ventos e o gemer das cascatas!

O mugido do gado e o mistério da selva!

\footnotetext{
${ }^{5}$ Cf. DANTAS (2001).
} 


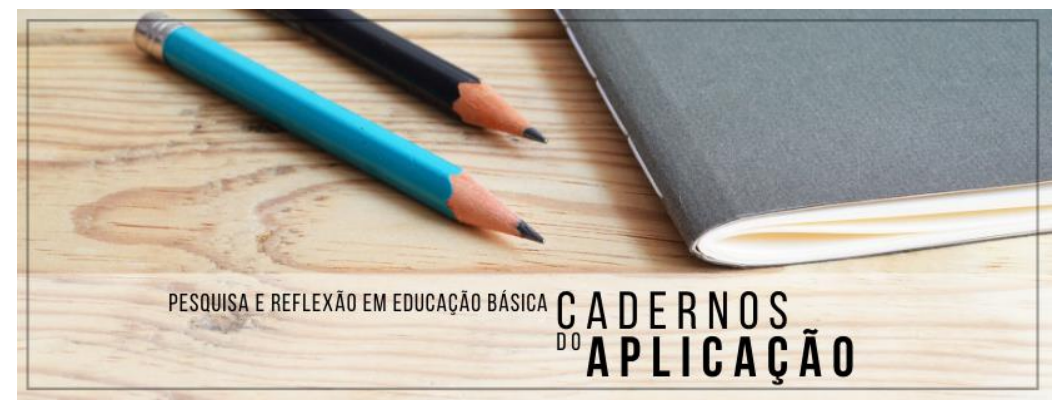

Cadernos do Aplicação

https://seer.ufrgs.br/CadernosdoAplicacao

Publicação Ahead of Print

ISSN 2595-4377 (online)

Porto Alegre | jul-dez. 2021 | v.34 | n.2

Esses recortes mostram que o autor promove um rompimento com o paradigma da negligência da história dos negros no Rio Grande do Norte, contudo não faz isso de forma direta, mas sim por meio da figura do vaqueiro - um dos principais símbolos da cultura potiguar - que tem na sua formação a presença de homens negros escravizados e libertos.

Henrique Castriciano é considerado por muitos um escritor romântico ou, ainda, pósromântico, para usar da expressão de Araújo (2004), mas, curiosamente, o poema Aboio traz alguns elementos que seriam utilizados pelo modernismo anos depois, tais como: i) a temática nacionalista, desta vez por meio do sertanejo; ii) a forte influência do ambiente na construção poética e; iii) a forma poética mais livre.

A obra aborda uma temática de cunho realista, expondo as desigualdades e sofrimentos provocados pela seca no Nordeste, que tirou a vida de muitos e forçou a migração de diversas pessoas. A situação do sertanejo pode ser observada por meio do seguinte trecho:

Pois quem é que resiste à agonia sem nome

De sepultar os seus, mirrados pela fome?

É partir! É partir!

Põe um filhinho no ombro

Cede o outro à mulher, cheia de medo e assombro.

Segundo Costa (2013, p. 73), "o poema tende a se constituir por um princípio narrativo que reflete a estrutura de uma ordem social em função do modo de vida do homem sertanejo historicamente recorrente, tal qual o ciclo do inverno e da seca." Temas que envolviam problemas sociais ganharam mais ênfase durante o período modernista, especificamente na década de 30, como Graciliano Ramos em sua obra, Vidas Secas.

A linguagem regional pode ser observada a partir de alguns termos, como à beira dos currais, galo-de-campina, aboio, e também pela presença de diversos elementos da natureza como, por exemplo; juazeiro, oiticica, jandaia, jaçanãs, entre outros. Percebe-se que a linguagem se aproxima do coloquial, auxiliando na construção da realidade regional retratada. Contudo não é um poema regional.

Em 1920, Aboio fora publicado na Revista do Brasil, o periódico mais importante e relevante do meio intelectual e literário da época, dirigido por Monteiro Lobato, que foi o responsável por tamanha visibilidade. Por meio da difusão da Revista, o poema potiguar 


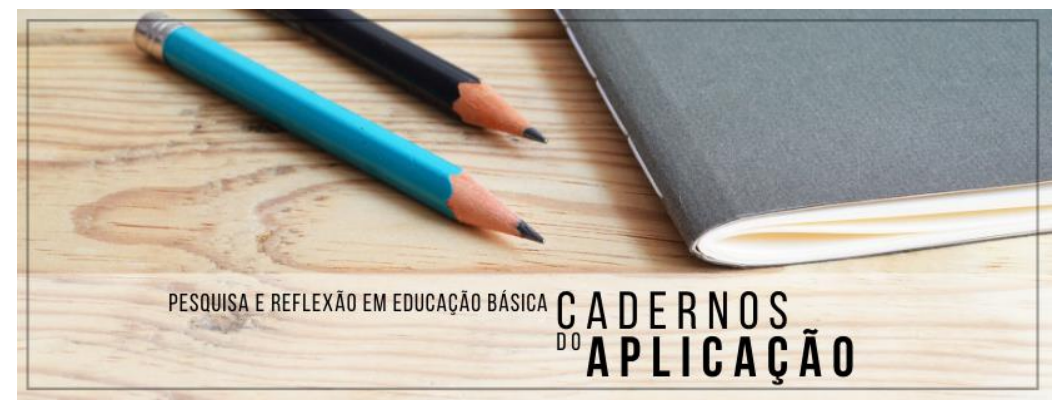

Cadernos do Aplicação

https://seer.ufrgs.br/CadernosdoAplicacao

Publicação Ahead of Print

ISSN 2595-4377 (online)

Porto Alegre | jul-dez. 2021 | v.34 | n.2

alcançou o público do sudeste, transbordando sua região e adentrando no eixo da literatura suprarregional.

Importante frisar que a transposição de regional para suprarregional precisa ser consciente, isto é, há a necessidade de romper com o discurso da tradição regional para alcançar um sistema literário mais amplo (ARENDT, 2011). É possível inferir, por meio do mercado editorial, que Henrique Castriciano tivesse esse desejo, contudo é apenas uma inferência que precisa ser analisada à luz de outros fatores que corroboram para que um autor se torne suprarregional: os locais de edição, qual era o público-leitor, a temática que ultrapassa as imagens locais, aos rumos da crítica literária após a morte do autor, etc. Note-se que a consciência é um ponto importante, mas não o único condicionante para tratar autor/obra como suprarregional.

Há um consenso local de que Auta de Souza era uma escritora negra, a mesma coisa se aplica ao seu irmão Eloy de Souza, porém em relação a Henrique Castriciano não encontramos dados que se referissem a ele como escritor afrodescendente, exceto o trabalho de Thiago Gonzaga (2014), mas ainda sim sem um devido aprofundamento sobre esse escritor em específico. O certo é que essa falta de dados, de autoafirmação desses escritores potiguares se explica pela dificuldade de assumir a identidade negra e a imitação dos padrões europeus como forma de inserção no mundo político, social, cultural e literário (DUARTE, 2002).

Se Auta de Souza e seu irmão Henrique Castriciano não abordaram a figura do negro de forma direta em seus poemas, não se pode falar a mesma coisa do poeta, branco, Segundo Wanderley. Considerado um dos maiores poetas do Rio Grande do Norte, Wanderley tem uma produção poética atuante em prol do abolicionismo - uma forte evidência da influência de Castro Alves na escrita romântica do poeta potiguar.

No poema $A$ voz da justiça, há uma conclamação pelo fim da escravidão e um recado direto a quem, porventura, ainda não tenha a consciência da falta de humanidade com a população escravizada. É uma espécie de poema-panfleto da causa abolicionista, o que já insere Segundo Wanderley não só em consonância com a estética literária vigente, o Romantismo, bem como já mostra, de forma muito límpida, o posicionamento do escritor: 


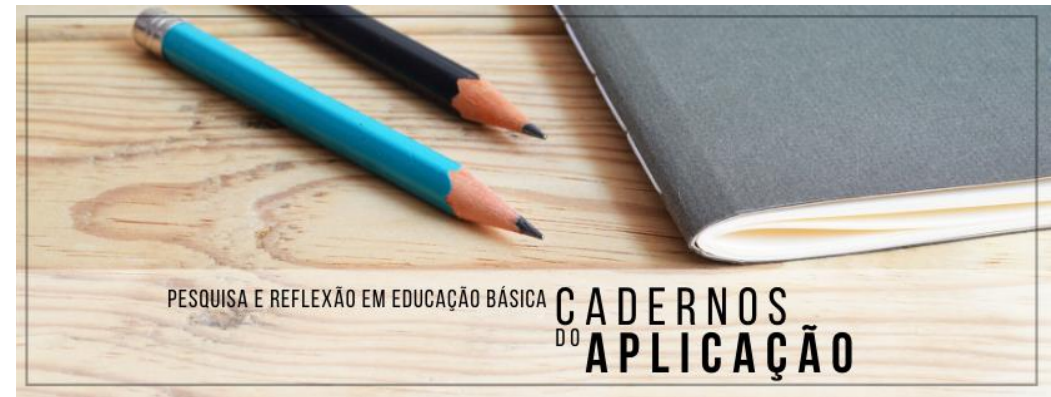

Cadernos do Aplicação

https://seer.ufrgs.br/CadernosdoAplicacao

Publicação Ahead of Print

ISSN 2595-4377 (online)

Porto Alegre | jul-dez. 2021 | v.34 | n.2

\begin{abstract}
Rompam-se as ímpias cadeias
Dos pulsos da escravidão

E delas façam-se escadas

P'ra o templo da redenção;

Abata-se o preconceito,

Salve-se a honra, o direito,

A consciência, o porvir,

E seja infame, precito,

Deste combate bendito

Quem recuar, quem fugir.
\end{abstract}

Mesmo sendo uma figura de expressão no Estado do Rio Grande do Norte e escrevendo de acordo com os modelos estéticos contemporâneos, a produção de Segundo Wanderley recai sobre o conceito de regional sem as devidas forças para romper essa barreira em seu tempo. Porém, é necessário considerar a temática da negritude nos seus poemas não só como forma de inseri-lo no Romantismo, mas como suprarregional e viabilizador da imagem do preconceito e exploração que a população negra sofrera.

Essa ruptura com o pensamento dos contemporâneos fica mais evidente quando lançamos o olhar para poemas que foram publicados no pós-abolicionismo no Estado potiguar e que defendiam o regime da escravidão. Exemplo disso é o poema Mandamentos, publicado no jornal A República, assinado por Bento José Taveira, de Ceará-Mirim, em 1899:

O Conde d'Eu é francês.

De Luiz Felipe é parente

Recorde de sua gente

Luiz quinze dezesseis

Evite, pois, sua vez

E não provoque a nação

Pela louca pretensão

De uma mulher orgulhosa

Soberba e ambiciosa

Que quer nossa escravidão.

\title{
[...]
}

A vossa legislação

Foi quem o véu levantou

Nossos escravos alforriou ${ }^{6}$

Sem haver compensação:

Estimulou a nação,

\footnotetext{
${ }^{6}$ No original, o publicado no jornal, a palavra é "forrou". Entendemos como uma variação do sintagma alforriar, daí a atualização.
} 


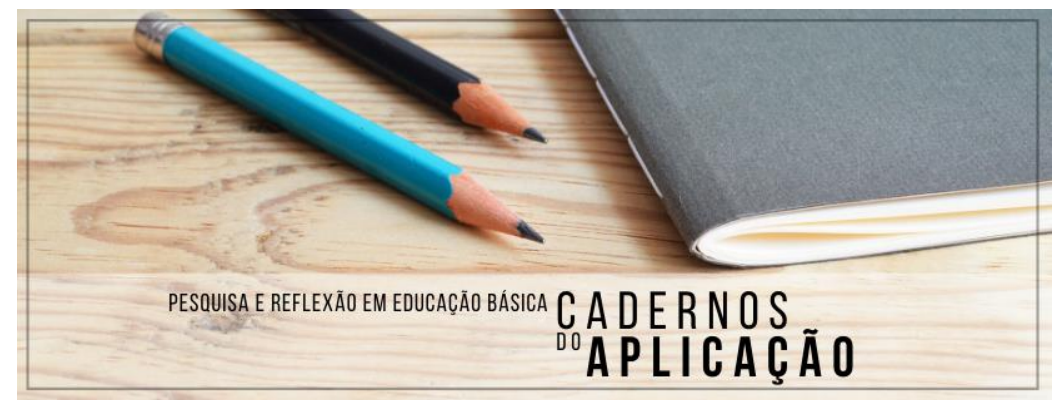

Cadernos do Aplicação

https://seer.ufrgs.br/CadernosdoAplicacao

Publicação Ahead of Print

ISSN 2595-4377 (online)

Porto Alegre | jul-dez. 2021 | v.34 | n.2

Querer também liberdade

Findar a hereditariedade,

Não aceitar Monarquia

Terminar a dinastia

É uma necessidade.

O poema é uma miscelânea de preconceitos contra a mulher e o negro. A pretexto de defender a República, começa por criticar a princesa Isabel pela Lei Áurea de 1888 e se coloca na posição de pretenso escravizado por conta dos efeitos da abolição da escravidão. O poetamunicipal $^{7}$ continua na defesa da República e reclamando a falta de uma compensação pelo fim da política escravocrata.

O fato de Segundo Wanderley não compartilhar desses posicionamentos já seria o bastante para entendê-lo como voz dissonante, contudo seu poema $A$ voz da justiça não só faz questão de deixar claro isso, como aponta o caminho: pela justiça.

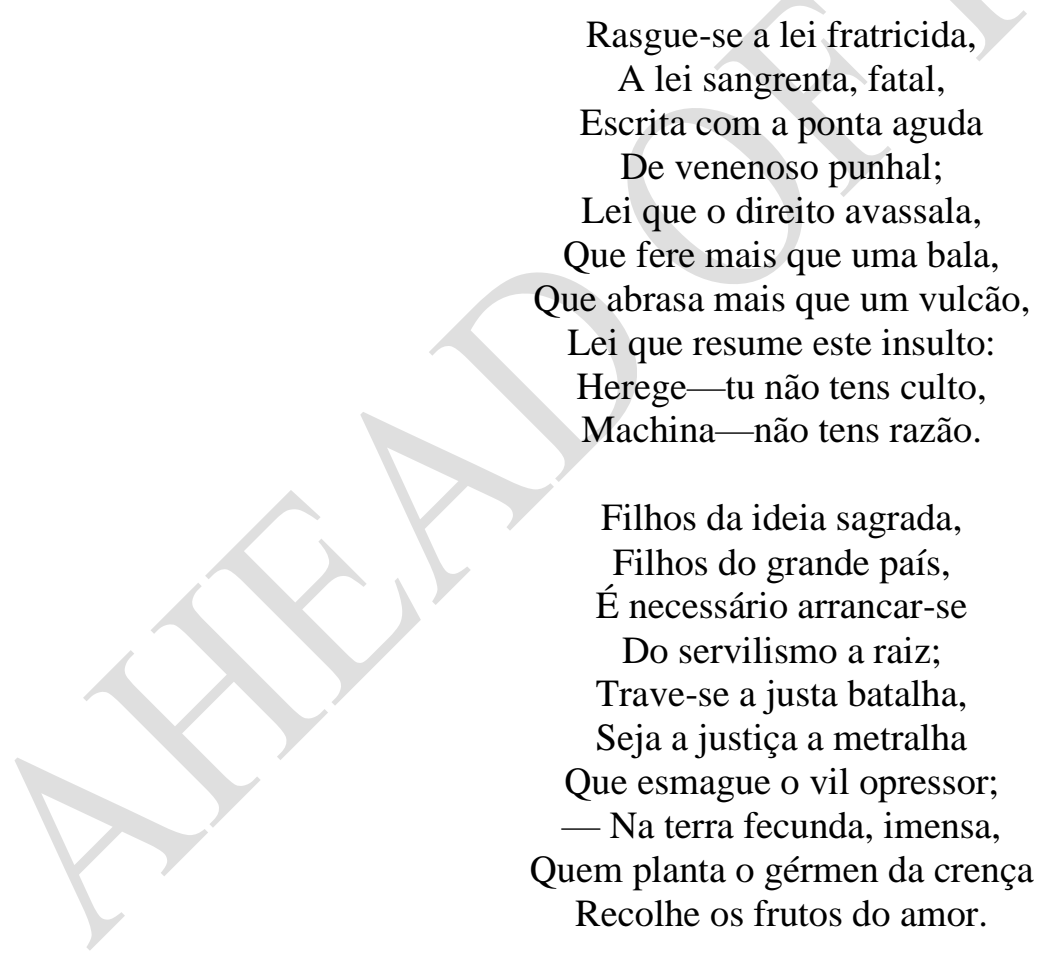

$[\ldots]$

\footnotetext{
${ }^{7}$ A expressão é utilizada para reforçar a ausência de produções de Bento José Taveira, o qual provavelmente escrevera no âmbito da sua localidade configurando apenas aspirações poéticas, soma-se a isso o fato de serem estrofes com dez versos ABBAACCDDC se assemelhando a forma de poemas épicos, algo bastante anacrônico. Há a possibilidade de Bento Taveira ser um pseudônimo visto a publicação ser no jornal A República, fundado, em 1899, pelo primeiro governador do Estado do Rio Grande do Norte, Pedro Velho.
} 


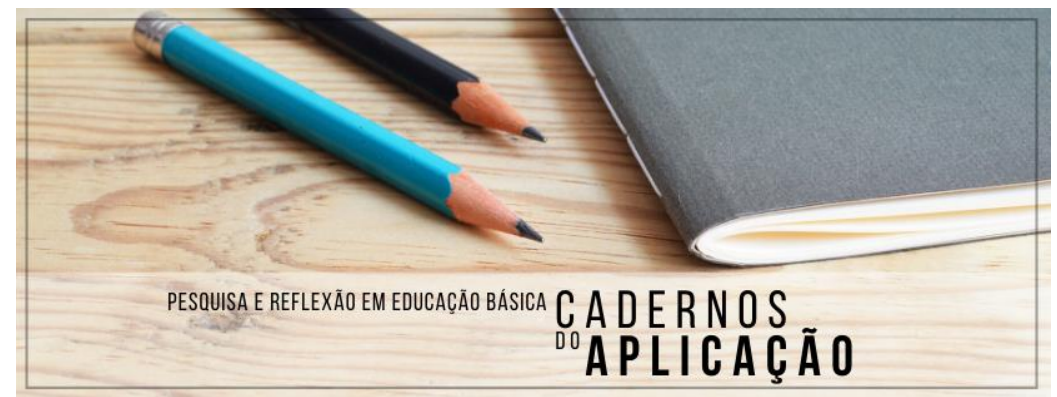

Cadernos do Aplicação

https://seer.ufrgs.br/CadernosdoAplicacao

Publicação Ahead of Print

ISSN 2595-4377 (online)

Porto Alegre | jul-dez. 2021 | v.34 | n.2

Enquanto houver mercenários

Sem alma, sem coração,

Que vendam, desnaturados,

O sangue de seu irmão;

Enquanto as negras ossadas

Servirem, que horror! de escadas

P'ra o trono vil de Caim,

Tudo se esvai, desparece,

Nada produz, nada cresce

Neste deserto sem fim.

\section{Considerações finais}

Este artigo tem como origem o projeto de pesquisa desenvolvido no Instituto Federal do Rio Grande - IFRN Campus Pau dos Ferros, com alunos dos cursos técnicos integrados de nível médio, o qual tratava sobre que imagem do negro, seja como autoria ou temática, é possível extrair da produção poética potiguar. Tínhamos também o objetivo de colocar em discussão o conceito de regional lançando nosso olhar para uma nova possibilidade apresentada por Arendt (2011), que é do suprarregional, isto é, a possibilidade de obras e autores furarem a bolha do regionalismo alcançando outro sistema literário mais complexo - o que até o momento ainda não houve um trabalho mais detalhado sobre essa particularidade que envolve as literaturas regionais, em especial, a potiguar.

Pensado antes do período da pandemia, a pesquisa precisou de adaptações visto as condições de biossegurança. Contudo, foi possível observar que a literatura potiguar, sendo constituída por meio de manifestações literárias tardias, deixou hiatos quando o assunto é a condição do negro no antes e pós-abolicionismo.

Mesmo em autores negros, como Auta de Souza, a temática do negro não aparece o que sugere uma ênfase mais teórica-estética no livro Horto com uma temática melancólica simbolizada por meio da natureza (ALVES, 2014). A imagem do negro em Auta de Souza não é avultada nem pelo simbolismo, nem pelo romantismo sentimental, momento que em se esperaria ao menos por aquilo que Cascudo (1998, p. 126) chamou de "figuras infinitamente humanas" na poesia de Auta.

Se a condição do negro e o preconceito no pós-abolição não foram capazes de fazer aflorar as imagens das dores humanas, mas ao menos uma imagem fica: a da não identificação 


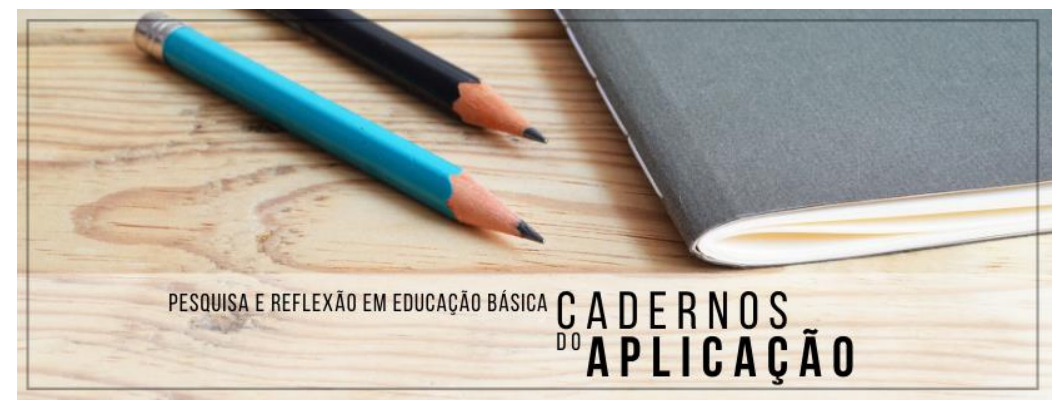

Cadernos do Aplicação https://seer.ufrgs.br/CadernosdoAplicacao

Publicação Ahead of Print

ISSN 2595-4377 (online)

Porto Alegre | jul-dez. 2021 | v.34 | n.2

como mulher negra. Isso se dá pela confluência de condicionantes históricos e culturais que estigmatizavam o negro e, consequentemente, impedia a assunção dessa identidade por muitos escritores - o que parece ser o caso de Auta de Souza.

A mesma coisa se dá com seu irmão Henrique Castriciano, com uma ressalva que o poeta publica o seu poema Aboio trazendo a temática do sertanejo, suas aventuras, a miséria, a exploração e que coloca o negro, de forma indireta, no seio desse cenário também, pois a população escravizada terá parte, no Rio Grande do Norte, na formação do homem sertanejo.

Já Segundo Wanderley é o único que coloca a problemática da escravidão na sua poesia. Dessa maneira não só contemporiza as imagens da população escravizada, como ensaia uma produção suprarregional por meio da assunção da causa abolicionista e da inserção no Romantismo.

De uma forma geral, esses três poetas conseguem romper a barreira geográfica do regional seja pela temática, por questões editoriais ou crítica literária. Levam a outros leitores e lugares temas regionais numa tentativa de tocar o universal. Porém, no que tange a presença do negro nessas produções, o pouco espaço e mesmo a ausência dessa discussão na poética de escritores negros, mas a persistência em se tornarem suprarregionais faz com que nossa compreensão perante esses poemas seja de dissidência com seus contemporâneos, isto é, não se encontram em perfeita sintonia com a produção local e isso fica evidente pela estética e/ou pela temática.

\section{Referências}

ALVES, Alexandre. Poesia submersa: poetas e poemas no Rio Grande do Norte 1900-1950, Volume I. Mossoró: Queima-Bucha, 2014.

ARAÚJO, Humberto Hermenegildo. Pós-Românticos no Rio Grande do Norte. In: LINO, Joselita Bezerra da Silva; SILVA, Francisco Ivan da. (Orgs.) Múltipla palavra: ensaios de literatura. João Pessoa: ideia, 2004.

ARENDT, João Claudio. Contribuições alemãs para o estudo das literaturas regionais. Pandaemonium ger. (Online), São Paulo , n. 17, p. 217-238, 2011. Disponível em: $\quad$ http://www.scielo.br/scielo.php?script=sci_arttext\&pid=S198288372011000100012\&lng=en\&nrm=iso. Acesso em: 07 mar. 2021.

CANDIDO, Antonio. Formação da literatura brasileira (momentos decisivos). Rio de Janeiro: Ouro sobre Azul, 2006. 


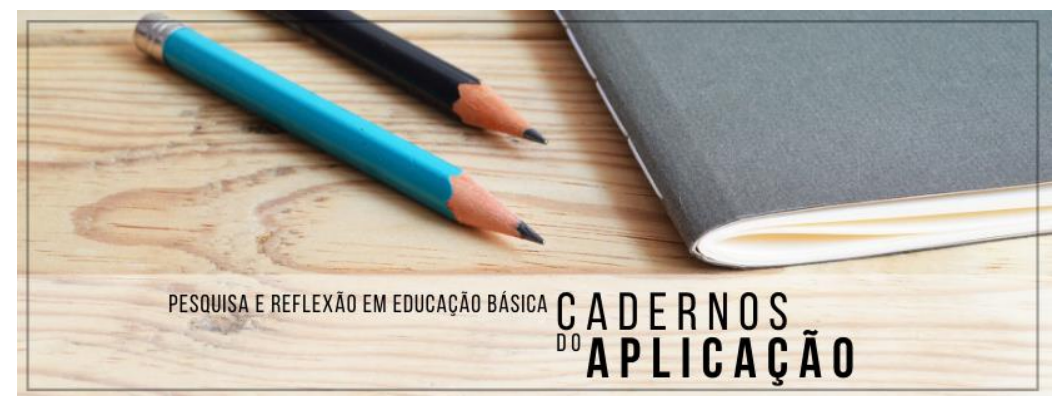

Cadernos do Aplicação https://seer.ufrgs.br/CadernosdoAplicacao

Publicação Ahead of Print ISSN 2595-4377 (online)

Porto Alegre | jul-dez. 2021 | v.34 | n.2

CASCUDO, Luís da Câmara. Alma patrícia: crítica literária. 2. ed., Natal: Fundação José Augusto, 1998.

CASTRICIANO, Henrique. Aboio. Revista do Brasil. São Paulo, ano V, v XIV, n 54, 1920, p. 127-131. Disponível em: http://bibdig.biblioteca.unesp.br/handle/10/26279. Acesso em: 07 mar. 2021.

COSTA, Maria Suely da. Canto do sertão: recortes da cultura popular em verso e prosa. In: LUCIO, Ana Cristina Marinho; MACIEL, Diógenes André Vieira (orgs.). Memórias da Borborema: reflexões em torno de regional. Maciel (Org.). Campina Grande: Abralic, 2013, p. 67-85).

DUARTE, Eduardo de Assis. Notas sobre a Literatura Afro-Brasileira. In: SCARPELLI, Marli Fantini; DUARTE, Eduardo de Assis (orgs.). Poéticas da diversidade. Belo Horizonte: UFMG/FALE, 2002, pp. 47-61.

GONZAGA, Thiago. Presença do Negro na Literatura Potiguar e Outros Ensaios. Natal: CJA Edições, 2014.

JOACHIMSTHALER, Jürgen. A literarização da região e a regionalização da literatura. Antares (Letras e Humanidades), Caxias do Sul, $\mathrm{n}^{\circ} 2$, jul/dez 2009. Disponível em: <http://www.ucs.br/etc/revistas/index.php/antares/article/view/400/330>. Acesso em: 07 mar. 2021.

MATTELART, Armand; NEVEU, Érik. Introdução aos estudos culturais. Tradução de Marcos Marcionilo. São Paulo: Parábola Editorial, 2004.

OLIVEIRA, Francisco Humberlan Arruda de.; CAMARGO, Kátia Aily Franco de. O nomadismo como função estética nos contos de Lima Barreto. Revista Odisseia, v. 4, n. 2, p. p. 16 - 33, 7 ago. 2019. Disponível em: https://periodicos.ufrn.br/odisseia/article/view/18297. Acesso em: 07 mar. 2021.

RIBEIRO, Celeste de Sousa. Perspectivas imagológicas. Apresentação. In: Ribeiro, Celeste de Sousa (org.). Imagologia. Coletânea de ensaios de Hugo Dyserinck I. São Paulo, Instituto Martius-Staden, 2005.

SOUZA, Auta de. Horto. 5. ed. Natal: EDUFRN, 2001.

TAVEIRA, Bento José. Mandamentos. A República. Natal, ano I, n 11, 1889, p. 3-4. Disponível em: http://memoria.bn.br/DocReader/138924/4391889. Acesso em: 07 mar. 2021.

WANDERLEY, Manoel Segundo. Poesias. Natal: Tipografia d'A República, 1910.

Data de submissão: 16/03/2021

Data de aceite: 20/04/2021

DOI: https://doi.org/10.22456/2595-4377.112183 